Viso - Cadernos de estética aplicada Revista eletrônica de estética

ISSN 1981-4062

$N^{\circ} 4$, jan-jun/2008

http://www.revistaviso.com.br/

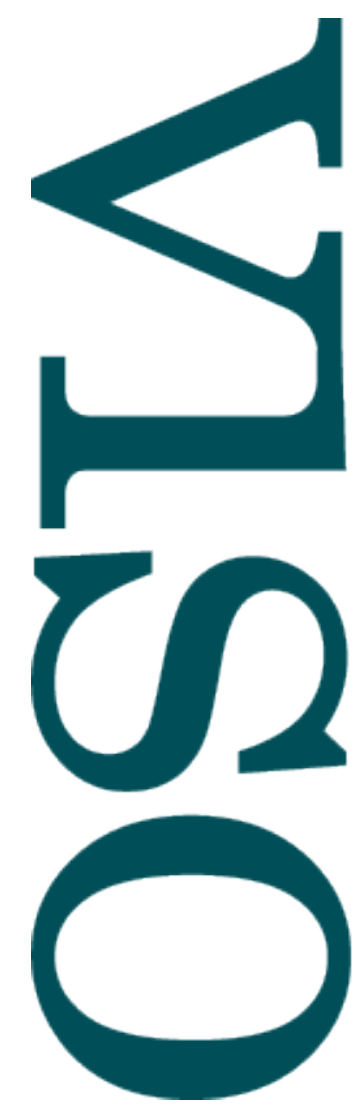

\title{
O doce encanto da pintura e da escultura no Elogio de Helena de Górgias de Leontinos Aldo Dinucci
}




\title{
RESUMO
}

O doce encanto da pintura e da escultura no

\section{Elogio de Helena de Górgias de Leontinos}

Górgias de Leontinos, no Elogio de Helena, enfatiza o caráter sedutor das palavras em relação às almas humanas. A sedução das palavras, porém, não é senão um caso especial da sedução das coisas sensíveis e divinas sobre os homens, sedução que muitas vezes constrange e afoga o homem, que se vê imerso num mundo trágico onde os únicos objetos que ele pode contemplar com doçura e liberdade e sem o perigo de perder-se são as pinturas e as esculturas.

Palavras-chave: sofística - filosofia clássica - Górgias de Leontinos

\begin{abstract}
The sweet seduction of paiting and sculpture in Gorgias Leontini's Encomium of Helen

Gorgias Leontini, in Encomium of Helen, underlines the seductive character of words to the human souls. This seduction, however, is nothing but a special case of the seduction of natural and divine things upon man, which many times constrains and overpasses him. In these situations, one sees oneself submerged in a tragic world where the only objects one can be contemplate with sweetness, liberty and without the danger of loosing oneself are paintings and sculptures.
\end{abstract}

Keywords: sophistic - classical philosophy - Gorgias Leontini 


\section{DINUCCI, A. "O doce encanto da pintura e da escultura no Elogio de Helena de Górgias de Leontinos". In: Viso: Cadernos de estética aplicada, v. II, n. 4 (jan-jun/2008), pp. 74-83.}

DOI: $10.22409 / 1981-4062 / v 4 i / 57$

Aprovado: 29.05.2008. Publicado: 30.06.2008.

(C) 2008 Aldo Dinucci. Esse documento é distribuído nos termos da licença Creative Commons Atribuição-NãoComercial 4.0 Internacional (CC-BY-NC), que permite, exceto para fins comerciais, copiar e redistribuir o material em qualquer formato ou meio, bem como remixá-lo, transformá-lo ou criar a partir dele, desde que seja dado o devido crédito e indicada a licença sob a qual ele foi originalmente publicado.

Licença: http://creativecommons.org/licenses/by-nc/4.0/deed.pt_BR

Accepted: 29.05.2008. Publicado: 30.06.2008.

(C) 2008 Aldo Dinucci. This document is distributed under the terms of a Creative Commons Attribution-NonCommercial 4.0 International license (CC-BY-NC) which allows, except for commercial purposes, to copy and redistribute the material in any medium or format and to remix, transform, and build upon the material, provided the original work is properly cited and states its license.

License: http://creativecommons.org/licenses/by-nc/4.0/ 
O exame de Górgias do mito de Helena revela uma afirmação característica do pensamento gorgiano, bem como do trágico em geral: por mais virtuoso que seja um ser humano, isso não garante que sobre ele não se abatam calamidades e infortúnios. Untersteiner ${ }^{1}$ observa que Górgias não escolhe por acaso personagens míticos, exemplos de beleza (Helena) e sabedoria (Palamedes): Górgias busca atualizar as antigas formas da mitologia, explicando seu comportamento e suas vicissitudes através de sua cosmovisão trágica. Helena, por exemplo, apesar da excelência de sua beleza, não foi privada de terríveis infortúnios. Palamedes, apesar de sua sabedoria, foi condenado injustamente à morte. Assim, a perfeição de uma virtude em um ser humano não pode torná-lo imune às intempéries do devir: o ser humano é, para Górgias, sempre limitado e frágil diante dos deuses e da natureza.

Sendo limitado e frágil, o homem é muitas vezes constrangido no seu agir. E a questão central em torno da qual gira o Elogio de Helena é justamente a constatação da contradição entre o decreto da necessidade que causa um infortúnio e a condenação moral de uma ação humana, considerada como razão deste infortúnio. ${ }^{2}$ Justamente por $^{2}$ este motivo, Górgias dirá ser tarefa dos justos corrigir a distorção gerada por aqueles que, sendo injustos, são afortunados e por aqueles que, mesmo sendo justos, conhecem a calamidade (Cf. Górgias, Epitáfio).

No Elogio de Helena, Górgias buscará mostrar que as ações de Helena podem ter sido guiadas pela necessidade, isto é, que ela pode ter agido sob o influxo de forças que, quando exercem uma influência irresistível e decisiva sobre o ser humano, tornam-no incapaz de agir espontaneamente ou de modo autônomo.

Em primeiro lugar, Górgias argumenta que um mortal não pode impedir o desejo de um deus, pois os deuses são mais poderosos que os homens:

Pois é impossível opor-se, pela diligência humana, ao desejo do divino. Pois é por natureza não o mais forte ser detido pelo mais fraco, mas o mais fraco pelo mais forte ser comandado e conduzido, e, por um lado, o mais forte comanda, por outro, o mais fraco obedece. O divino [é] mais forte que o homem, tanto pela força e pela sabedoria, quanto pelas outras coisas. Com efeito, se é necessário atribuir a responsabilidade à Fortuna e ao divino, neste caso é necessário libertar Helena da ignomínia. ${ }^{3}$ (Elogio de Helena, 6)

Górgias, portanto, observa que os homens não têm como rivalizar com o poderio divino e, por essa razão, têm de se submeter aos caprichos dos deuses. Para Górgias, entretanto, essa afirmação do direito do mais forte é aplicada tão somente à esfera teológica:

Não há [...] lugar para reconhecer neste tema aquele da lei do mais forte que domina o mais fraco, entendido num sentido estritamente político. Aqui, o conceito é essencialmente religioso e inclui, por conseqüência, para a divindade em todas as suas manifestações, os atributos da violência, da sabedoria de suas outras disposições, tanto materiais quanto espirituais. ${ }^{4}$ 
De fato, para Górgias, a violência como expressão do divino não é normativa para a conduta humana, o que fica claro pelo seguinte trecho do Elogio de Helena:

Se foi arrebatada à força e ilegalmente submetida e injustamente tratada com insolência, é evidente que agiu ilegalmente quem tanto [a] arrebatou quanto [a] tratou com insolência, [enquanto] ela, sendo tanto raptada quanto ultrajada, teve má fortuna. Com efeito, [é] o bárbaro, o qual lançou mãos ao bárbaro empreendimento, que merece [a pena], tanto pelo discurso e pela lei, quanto pela ação [...] Sendo submetida à força, privada da pátria e afastada dos amigos, como não, com razão, ela antes provocaria a piedade que a difamação? Pois ele fez coisas terríveis, ela sofreu a ação: com efeito, [é] justo ter piedade dela e a ele odiar. (Elogio de Helena, 7 )

Assim, vemos que o rapto de Helena é tomado como ilegal e imoral por Górgias. Desta forma, aqueles que agem assim estão sujeitos às punições de acordo com a lei. Dizer que o princípio do direito do mais forte é afirmado por Górgias em sentido estritamente teológico equivale a dizer que Górgias utiliza a tese do direito do mais forte como um princípio descritivo, aplicável apenas à esfera divina, mas inaceitável como princípio normativo para a conduta social. Para os gregos, o elemento divino, enquanto poderoso, manifesta-se sobretudo através da violência. $O$ comportamento belicoso e selvaticamente sexual atribuído aos deuses na mitologia grega, se não é censurável no âmbito divino (assim como não podemos censurar a natureza por produzir terremotos, enchentes e outras catástrofes naturais), é com certeza descrito por Górgias como criminoso quando seu autor é um ser humano. "Esta concepção do divino como 'violência'," - observa Untersteiner - "na medida em que ela lembra um estado primitivo e [...] demoníaco da representação do divino, permanece misterioso, em contradição com as categorias da ética humana" ${ }^{5}$

Se os mortais não podem se opor aos anseios divinos, por serem fracos e por disporem de ínfima sabedoria em relação aos deuses, também muitas vezes não podem resistir aos seres corpóreos que os rodeiam: Pois, diz-nos Górgias (Elogio de Helena, 15), "as coisas que vemos têm a qualidade que cabe a cada uma e não a que queremos. Através da visão, a alma é atingida também em seus modos de pensar e agir". Assim, a alma é afetada pelos corpos que a rodeiam e, como veremos a seguir, essa influência pode arrastá-la num turbilhão.

Sabemos que Górgias caracteriza o lógos como sedutor e, por esta razão, como persuasivo. Mas o lógos, para Górgias, é coisa sensível de "corpo pequeniníssimo e invisibilíssimo" (Elogio de Helena, 8). E o mesmo caráter sedutor e persuasivo, capaz de perturbar a mente, é comum às coisas sensíveis em geral. Untersteiner crê que Górgias estende o poder do lógos às próprias coisas, ou seja, que as coisas exprimem cada qual o seu próprio logos. ${ }^{6}$ Porém, não vemos qualquer indicação, no Elogio de Helena e nas outras obras de Górgias de que este seja o caso. Vemos, outrossim, que Górgias considera o real como exclusivamente composto pelas coisas sensíveis, entre as quais ele conta o lógos. 
Assim, da mesma forma que diferentes tipos de lógos causam diferentes tipos de efeitos nos ouvintes, as outras coisas sensíveis se dividem também quanto ao tipo de reação que provocam naqueles que as percebem. Górgias descreve primeiramente os efeitos negativos da sedução que as coisas sensíveis exercem sobre os homens:

Com efeito, por exemplo, quando a vista contempla a formação e os corpos dos inimigos, diante do armamento de bronze e de ferro, tanto das armas de defesa quanto das armaduras, a visão é agitada e agita a alma, de modo que freqüentemente, tomados de terror, [muitos] fogem do perigo iminente como se este fosse presente [...] Pois a maneira de ser habitual, pela lei vigorosa, é banida graças à visão, a qual, chegando [à alma], faz negligenciar tanto o que é decidido pela lei quanto o bem que advém pela vitória. A partir disso, alguns que vêem coisas terríveis perdem, neste preciso momento, a presença de espírito: de modo que o medo extingue e expulsa a reflexão. Muitos recaem em inúteis sofrimentos, em terríveis doenças e em loucuras difíceis de curar. (Elogio de Helena, 15-17)

Assim, vemos Górgias nos dizer que, pela visão das coisas, a alma é atingida [tupoutai] (15), pois a visão é agitada [etarachthe] e agita [etaraxe] (16) a alma, gravando nela as imagens das coisas (17). Os efeitos maléficos da visão das coisas sensíveis podem deixar muitos tomados de terror [ekplagentes] (16). Diante de tais visões, alguns perdem a presença de espírito (17), fazendo com que a maneira habitual de viver [sunetheia] seja banida (21). O medo, resultado de tais visões, extingue [apesbese] e expulsa [exelasen] a reflexão [noema], podendo muitas vezes levar à loucura (17).

Górgias, imediatamente a seguir, generaliza esta capacidade comum a muitas coisas sensíveis de afetar de modo maléfico a alma, dizendo que "muitas coisas apavorantes são omitidas [deste discurso], mas as coisas omitidas têm o mesmo valor que as coisas ditas" (17).

Górgias fala também das coisas sensíveis que provocam desejos sexuais nos homens e nas mulheres. As coisas eróticas, graças ao influxo divino (moralmente ambíguo), fazem nascer [energazetal] desejos sensuais [erota] e paixão por algo ausente [poton] (18):

\footnotetext{
Numerosos corpos (entre numerosos corpos e coisas) fazem nascer desejos sensuais e paixão em numerosos homens. Se, com efeito, o olhar de Helena foi atingido pelo desejo pelo corpo de Alexandre e transmitiu o combate de Eros à alma, que há de extraordinário? Se ele, sendo um deus, tem o poder divino dos deuses, como seria possível o mais fraco negá-lo e afastá-lo de si? Se for uma doença humana e um erro cometido por um falso saber da alma, não deve como erro ser criticado, mas como infortúnio: foi, pois, como foi pelas ciladas da Fortuna, não pelos anseios do pensamento, e pelos constrangimentos de Eros, não pelos ardis da arte. (Elogio de Helena, 18-19)
}

Assim, a sedução erótica dos corpos é simultaneamente outra forma de constrangimento divino. Esta afirmação quanto ao poder de Eros sobre os mortais através dos belos corpos não só encerra o Helena mas também o abre, quando Górgias nos diz que: 
Gerada a partir de tais circunstâncias, era divina a beleza [de Helena], e o que ela recebeu também não passou despercebido: a numerosos, de numerosos desejos de paixão acometeu. Por meio de seu corpo, muitos corpos reuniu de homens que aspiravam grandemente a grandes coisas, dos quais uns possuíam a grandeza da riqueza, outros a glória de nobre e antiga estirpe, outros ainda a boa constituição da própria força, outros, por fim, o poder da sabedoria adquirida. E todos chegavam sob a influência do invencível Eros, amante das honras da vitória. (Elogio de Helena, 4)

E Górgias fala dos efeitos benéficos da sedução das coisas sensíveis, caso em que são incluídos os produtos pinturas e esculturas:

Por um lado, quando os pintores produzem à perfeição um corpo e uma figura a partir de numerosos corpos e cores, encantam a visão, por outro lado, a criação de estátuas de homens e a produção de imagens dos deuses oferecem uma doce contemplação aos olhos. (Elogio de Helena, 18)

Entre os efeitos benéficos da visão das coisas sensíveis, vemos Górgias nos dizer que os pintores, com suas obras, encantam a visão [terpousi ten opsin] (18), e que as estátuas oferecem uma doce contemplação [thean edeian] (18) aos olhos. As pinturas e as esculturas são os únicos objetos aos quais Górgias não atribui a propriedade de arrastar e seduzir malignamente as almas humanas. Ao contrário dos diferentes discursos e de suas diferentes artimanhas e possibilidades de enganar, esses objetos produzem um encanto que não subjuga.

Assim, o lógos, coisa sensível entre as coisas sensíveis, se revela como um caso especial da sedução que os corpos em geral exercem sobre os sentidos e, conseqüentemente, sobre a alma humana. $\mathrm{O}$ afeto que tais coisas exercem é poderoso a ponto de coagir os homens, chegando a enlouquecê-los pelo terror que causam, pelo furor sexual que despertam: os corpos são fontes de paixões que espicaçam e dilaceram os mortais. Além de tudo isto, os anseios divinos, fundamentalmente trágicos, podem tragar o homem e acometê-lo de infortúnios cruéis e absolutamente imerecidos.

O Elogio de Helena, desta forma, não é apenas uma demonstração do poder do lógos, mas uma exposição do gigantesco poder das coisas sensíveis sobre os homens, poder que, por sua violência e por sua sedução, é capaz de retirar destes mesmos homens a autonomia, não importando o quão virtuosos sejam. Os homens são assim representados em toda a sua fragilidade, expostos às forças da natureza e dos deuses.

Porém, se, por um lado, as forças da natureza e dos deuses muitas vezes não condizem com as expectativas morais humanas, revelando-se violentas e indiferentes aos nossos anseios, por outro, as pinturas e as esculturas têm o poder de encantar a visão e oferecer uma doce contemplação sem a possibilidade de causar qualquer malefício àquele que se deleita com suas imagens. Se as forças da natureza e dos deuses têm o poder de subjugar o homem, coagindo-o, as pinturas e as esculturas são desfrutadas sem este perigo. Assim, podemos dizer que, para Górgias, esses objetos são como um oásis para o homem, que pode contemplá-los docemente e com eles se deleitar sem o 
risco de ser arrastado por Eros ou subjugado pelos deuses e pela natureza. Diante desses objetos, portanto, o homem se liberta tanto da natureza quantos dos deuses, contemplando-os, e, em devaneio, pode enfim repousar.

Mas, para Górgias, que propriedade é essa que belas pinturas e esculturas possuem que as distingue de todos os demais corpos? Temos poucas evidências para responder a isto. Encontramos a mais importante em um fragmento greco-sírio traduzido por Ryssel. ${ }^{7}$ Diz o fragmento:

Górgias [em sírio Gorgonias] disse: A extraordinária beleza de uma coisa oculta manifesta-se quando pintores experientes não a podem representar com as suas experimentadas cores. Então o seu importante esforço e a sua grande fadiga patenteiam um testemunho maravilhoso do esplendor que permanece oculto [...] Mas aquilo que nenhuma mão toca, nem nenhum olho vê, como o pode a língua expressar ou a orelha do ouvinte perceber?

O fragmento fala de uma beleza extraordinária de algo que se oculta, beleza que pode ser expressa por artistas habilidosos através da pintura (e, podemos inferir, também através da escultura). Esse maravilhoso esplendor que se oculta não é, certamente, algo transcendente ou da ordem do inteligível. Para Górgias, como podemos constatar pelo Tratado do Não-Ser, não há tal coisa como o ser ou a essência: o mundo é absolutamente concreto, corpóreo, e suas raízes trágicas se estendem para além da compreensão humana. O sensível, por outro lado, é constituído de forma difusa: partidário da tese das emanações de Empédocles, Górgias ${ }^{8}$ sustenta que todos os corpos exalam sem cessar partículas que nos atingem através dos olhos, do nariz, dos ouvidos, nos fazendo testemunhar suas presenças.

É a partir deste ponto, creio, que podemos ensaiar uma resposta à questão de por que as esculturas e as pinturas têm essestatus privilegiado no pensamento de Górgias. O real, para Górgias, é o oposto do que é para a ontologia: não é algo que se lança para além do sensível, mas é o próprio sensível em difusão. Os corpos que no mundo se encontram têm efetivamente uma natureza, mas que é resultante da interação de inúmeros fatores: por exemplo, a essência da baunilha não é algo transcendente, mas uma conjunção de fatores corpóreos (uma formulação química, diríamos hoje) oriunda da flor de uma certa espécie de orquídea. Eis, creio, o real para Górgias, que é expresso na última frase do fragmento acima e que aqui repetimos: "Aquilo que nenhuma mão toca, nem nenhum olho vê, como o pode a língua expressar ou a orelha do ouvinte perceber?" Em outros termos: o que ultrapassa a esfera da sensação é inexistente e inexprimível para nós, nossa realidade são estas sensações, essas texturas e superfícies, essas cores e tonalidades, essas formas e formatos que, incessantemente exalados pelos corpos, nos chegam difusamente pelo ar.

Mas, poder-se-ia indagar, isto não nos é acessível desde o momento em que nascemos e abrimos os olhos? Precisamos de pinturas e esculturas para percebermos o que sempre esteve presente para nós? Diante do que dissemos, nossa resposta é: sim, 
precisamos das belas pinturas e esculturas para termos acesso direto a essa concretude. Em nossa vida diária, dificilmente a experienciamos, porque os corpos se apresentam a nós mergulhados no fluxo contínuo das paixões. Como disse Górgias, alguns corpos nos despertam medo, outros, terror, outros ainda, desejos eróticos ardentes, e todos eles podem nos tragar e escravizar, enlouquecer e acuar. Porém, as pinturas e as esculturas são objetos privilegiados no mundo, são capazes de nos mostrar essa beleza do real que costuma de nós se ocultar, pois suas figuras, cores e formas podem finalmente se nos apresentar despidas das paixões que nos perseguem. Assim, a representação de uma batalha é vista em sua beleza concreta, sem o medo e o terror que a batalha real inspira. Assim, admira-se a escultura de um corpo belíssimo sem o risco de ser tragado pelo erotismo que o corpo belíssimo de carne e osso provoca. Também os animais que inspiram medo, como serpentes, leões e lobos, quando representados, perdem o potencial de atormentar e matar, e pode-se então contemplar sem risco sua beleza selvagem.

Portanto, aquilo que é apenas entrevisto em nossa vida diária, que passa ao segundo plano em razão de nossos temores e furores, somente nos é desnudado através de pinturas e esculturas produzidas por artistas hábeis. Estes objetos resgatam para nós o extraordinário e maravilhoso esplendor da concretude do mundo, concretude esta que, por estar sempre aí e por habitarmos nela, não nos é totalmente desconhecida, razão pela qual, quando finalmente desnudada por pinturas e esculturas, a reconhecemos e contemplamos com doçura, como algo há muito perdido, mas que, por sua beleza extraordinária, nunca deixa de estar para nós presente, apesar do esquecimento e da distância que nos são impostos pelas paixões.

\section{BIBLIOGRAFIA COMPLEMENTAR}

ARISTÓTELES. Retórica. Tradução de Antônio Pinto de carvalho. São Paulo: Technoprint, 1980.

AUBENQUE, P. Le problème de l'être chez Aristote. 2a. edição. Paris: Quadrige, 1994.

BETT. “The Sophists and Relativism” in Phronesis, n. 34 (1989), pp. 139-169.

BORNHEIM, G. O sentido e a máscara. 3a. edição. São Paulo: Perspectiva, 1992.

CASSIN. L'effect sophistique. Paris: Gallimard, 1995.

DIELS-KRANZ. Die Fragmente der Vorsokratiker. 6a. edição. Berlim, 1952.

DUPRÉEL. Lês sophistes Protágoras, Górgias, Hippias. Neuchatel: Griffon, 1948.

GOMPERZ, H. Sophistic und Rethoric. Leipzig, 1912.

GUTHRIE, W. K. C. History of Philosophy. v. 3. Cambridge: Cambridge University Press, 1969.

HOMERO. Odisséia. Tradução de Antônio Pinto de Carvalho. São Paulo: Abril Cultural, 1981.

ISÓCRATES. Discourses. (trad. La Rue Van Hook).Londres: Harvard University Press, 1964.

KERFERD, G. B. The Sophistic Moviment. 2a. edição. Cambridge: Cambridge University Press, 1984. 
LEVI, A. "Studi su Gorgia" in Discurso, XIV, 1941, pp. 38 ss.

MOURELATOS. "Gorgias on the Fonction of language" in SicGymn, XXXVIII, 1985, pp. 607- 638.

SEXTO EMPÍRICO. Complete Works. Tradução de R. G. Bury. 4a. edição. Londres: Harvard University Press, 1987.

VERNANT, P. Mito y Tragedia en la Grecia Antigua. vol. II. Tradução de Ana Iriarte. Madrid: Taurus, 1989.

* Aldo Dinucci é professor da UFS.

${ }^{1}$ UNTERSTEINER. Les Sophistes vol. 1. Tradução de Alonso Tordesillas. Paris: Vrin, 1993, p. 160.

2 Ibidem, pp. 161-2.

${ }^{3}$ Este e os demais trechos do Elogio de Helena são apresentados em minha tradução a partir do texto em grego.

${ }^{4}$ Ibidem, p. 163.

${ }^{5}$ UNTERSTEINER. Op. cit., p. 163.

${ }^{6}$ Ibidem, p. 179.

${ }^{7}$ BARBOSA \& CASTRO. Górgias: Testemunhos e Fragmentos. Lisboa: Colibri, 1993, p. 64.

${ }^{8}$ Cf. PLATÃO. Mênon, 76a. 